\title{
Optimal Portfolio of Products in a Polycrystalline Silicon Refinery
}

\author{
César Ramírez-Márquez ${ }^{\mathrm{a}}$, Edgar Martín-Hernández ${ }^{\mathrm{b}}$, Mariano Martín ${ }^{\mathrm{b} 1}$, Juan Gabriel \\ Segovia-Hernández ${ }^{\mathrm{a} 1}$ \\ a Universidad de Guanajuato, Campus Guanajuato, División de Ciencias Naturales y Exactas, \\ Departamento de Ingeniería Química, Noria Alta S/N, 20256, Guanajuato Gto., México. \\ b Universidad de Salamanca, Departamento de Ingeniería Química. Pza. Caídos 1-5, 37008 \\ Salamanca, España.
}

Total number of Pages: 16

Total number of Figures: 23

\begin{tabular}{|c|c|}
\hline Content & Page No \\
\hline $\begin{array}{l}\text { Distribution of gaseous and condensed species in the Si-O-C system, } \\
\text { under surrogate models (SM continuous line) and experimental data (ED } \\
\text { markers) }\end{array}$ & S2 \\
\hline $\begin{array}{l}\text { Calculated distribution of the chlorine-containing species, Temperature. } \\
\mathrm{P}=1 \mathrm{~atm} \mathrm{H} 2 / \mathrm{SiCl} 4=1 \mathrm{~mol} / \mathrm{mol} \text {. }\end{array}$ & S3 \\
\hline $\begin{array}{l}\text { Calculated distribution of the chlorine-containing species, Temperature. } \\
\mathrm{P}=20 \mathrm{~atm} \mathrm{H} 2 / \mathrm{SiCl} 4=5 \mathrm{~mol} / \mathrm{mol} \text {. }\end{array}$ & S4 \\
\hline Reboiler duty of the first column 1 varying the reflux ratio. & S5 \\
\hline $\begin{array}{l}\text { Molar flow [kmol/h] for each component in the Dome and Bottom of RDC } \\
\text { for TEOS } 0.985-0.99-0.995 \text { and energy requirements }[\mathrm{kJ} / \mathrm{h}] \text {. }\end{array}$ & S6-S10 \\
\hline $\begin{array}{l}\text { Molar flow [kmol/h] for each component in the Dome and Bottom of RDC } \\
\text { for } \mathrm{SiH} 4-\mathrm{SiH}_{2} \mathrm{Cl}_{2}-\mathrm{SiH}_{3} \mathrm{Cl} \text { and energy requirements }[\mathrm{kJ} / \mathrm{h}] \text {. }\end{array}$ & S11-S15 \\
\hline $\begin{array}{l}\text { Kilograms of polycrystalline silicon regarding different road surface } \\
\text { temperatures }(1373,1423 \text {, and } 1500 \mathrm{~K}) \text { and different mole fraction of } \mathrm{H} 2 \\
\text { (Surrogate Model by continuous lines and experimental data with } \\
\text { markers). }\end{array}$ & S16 \\
\hline
\end{tabular}

\footnotetext{
${ }^{1}$ Corresponding autor. Juan Gabriel Segovia Hernández (gsegovia@ugtomx.onmicrosoft.com) and Mariano Martín.mariano.m3@usal.es
} 


\section{S.M.1 Thermal carboreduction}

In Figure S1, it can be seen that the species diagram obtained by the surrogate model (presented in section 2.2.1) displayed by continuous lines and with markers the experimental data obtained by Wai and Hutchison (1989), practically obtains the same species diagram. Hence, it can be said that the model predicts thermal carboreduction in an excellent way.

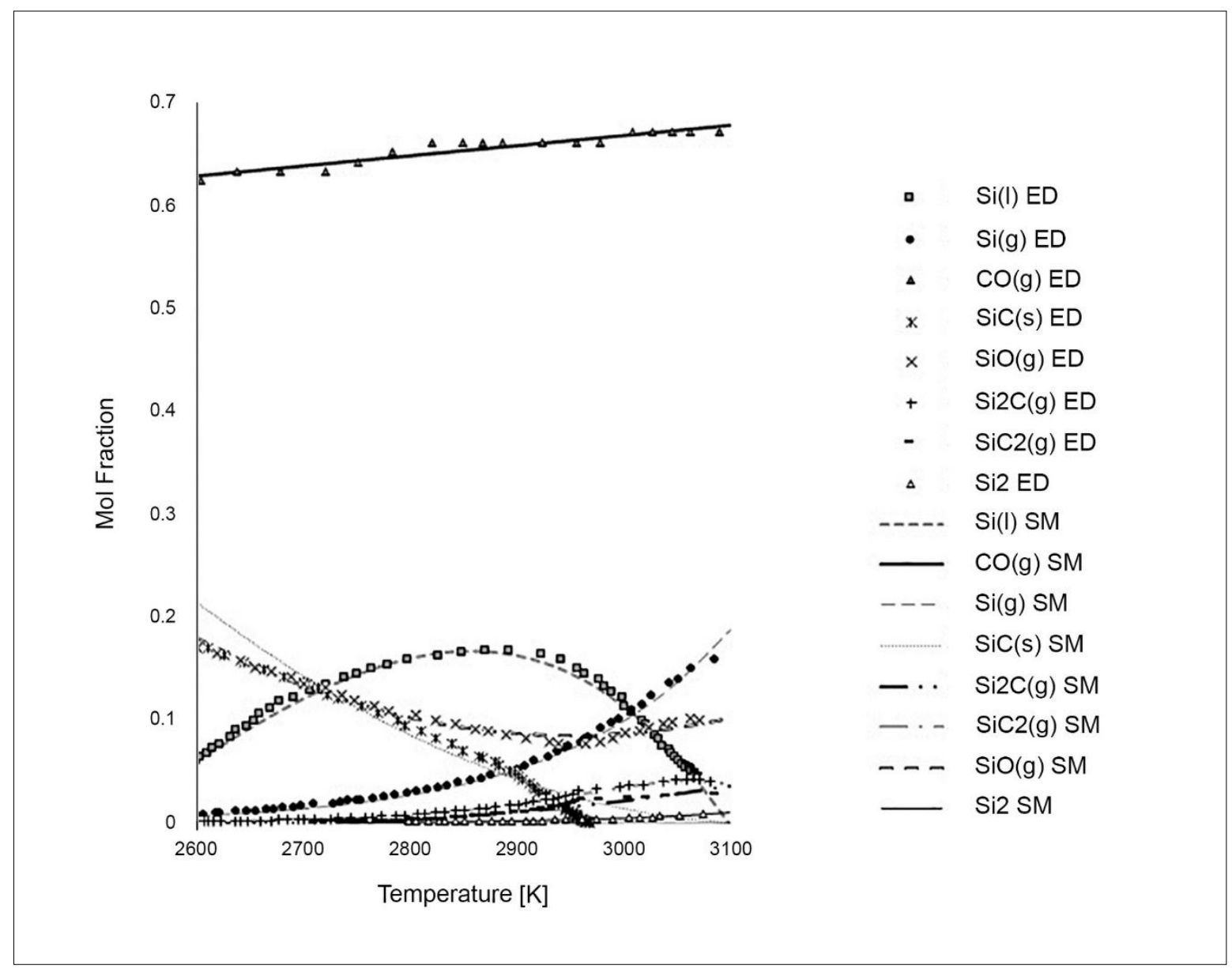

Fig. S1. Distribution of gaseous and condensed species in the Si-O-C system, under surrogate models (SM continuous line) and experimental data (ED markers). 


\section{S.M.2 Hydrochlorination Reactor}

Once the model in Section 2.2.2 is obtained, Figure S2 shows the species distribution obtained for the reaction of chlorosilane synthesis at the conditions of $1 \mathrm{~atm}$ and a ratio of 1 to 1 of $\mathrm{H}_{2}-\mathrm{SiCl}_{4}$ (SM by continuous lines). These conditions are exemplified by Ding, et al., (2014), and it can be seen that the species distribution diagram is the same as the ones shown by the authors (ED markers). When creating a model that takes into account the variation in temperature, pressure and supply ratio of $\mathrm{H}_{2}-\mathrm{SiCl}_{4}$, the species diagram is obtained with the surrogate model (as seen in Figure S3 by continuous lines ) and with markers the experimental data obtained by Ding, et al., (2014). Therefore, it can be said that the model predicts the synthesis reaction process effectively.

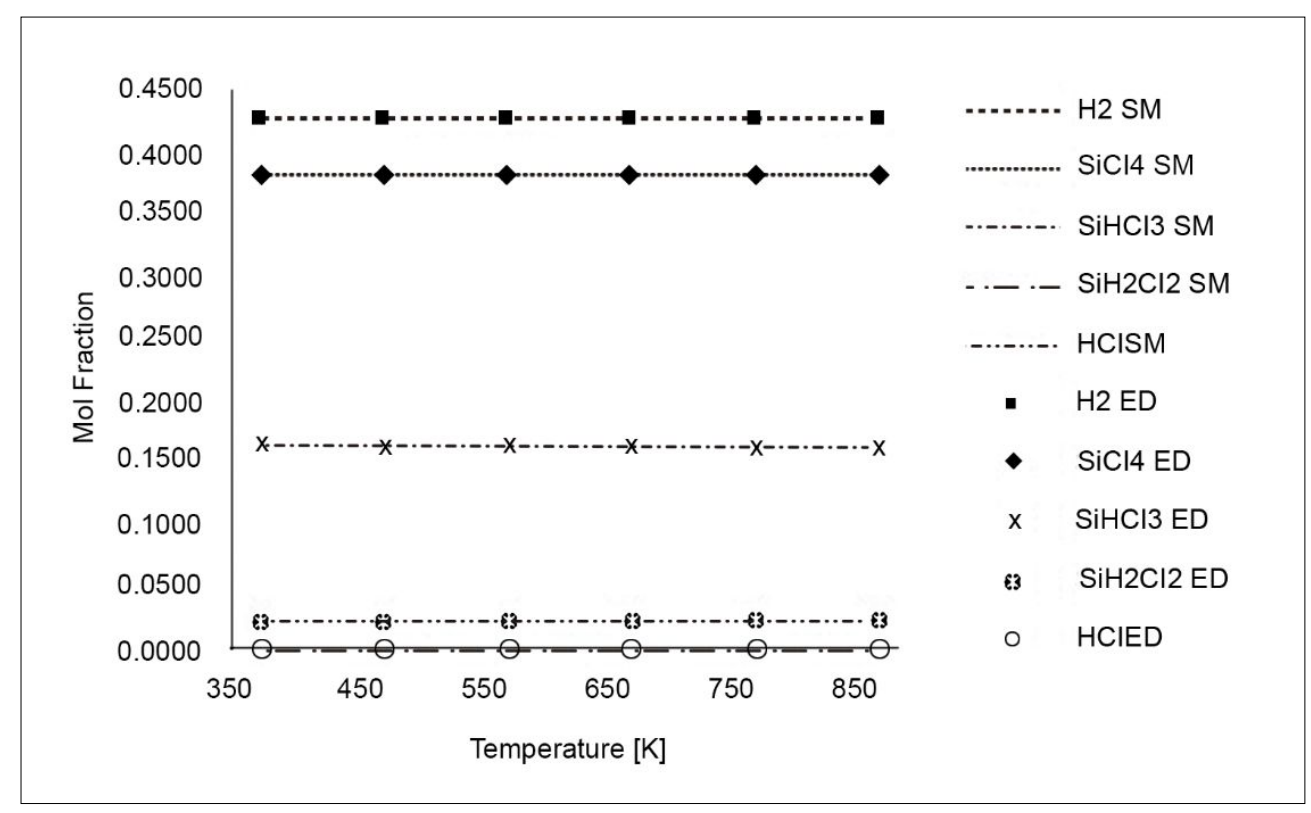

Fig. S2. Calculated distribution of the chlorine-containing species, Temperature. $\mathrm{P}=1 \mathrm{~atm}$ $\mathrm{H}_{2} / \mathrm{SiCl}_{4}=1 \mathrm{~mol} / \mathrm{mol}$. 


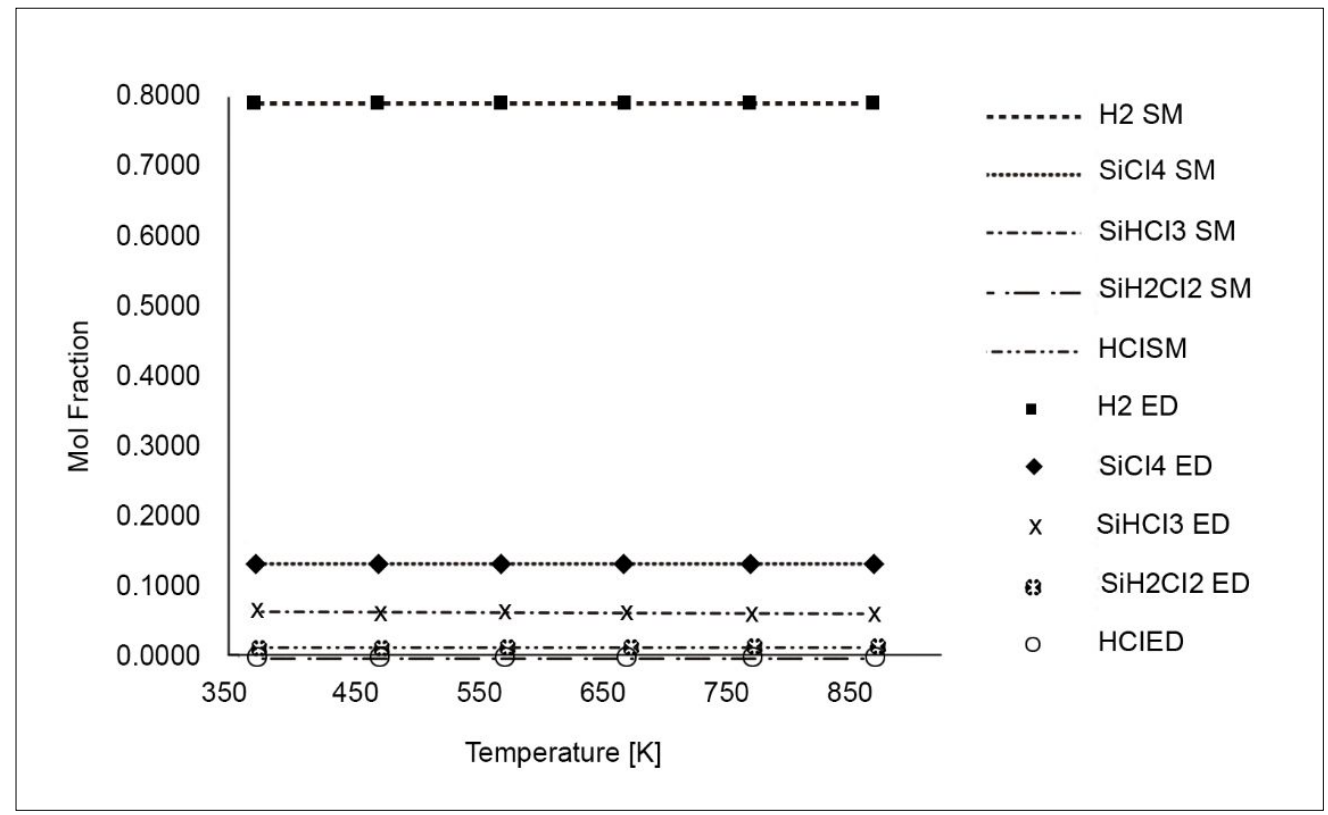

Fig. S3. Calculated distribution of the chlorine-containing species, Temperature. $P=20 \mathrm{~atm}$ $\mathrm{H}_{2} / \mathrm{SiCl}_{4}=5 \mathrm{~mol} / \mathrm{mol}$. 


\section{S.M.3 Separation and purification}

Figure S4 (section 2.2.3) shows the reboiler duty by the surrogate model, and the similarities are shown of the values that Aspen Plus $₫$ offers, this Figure demonstrates that the surrogate models obtained in separation and purification for the obtention of energy requirement are reliable. The same behavior for the thermal duty of the first column condenser as well as the energy requirements of the second column can be observed.

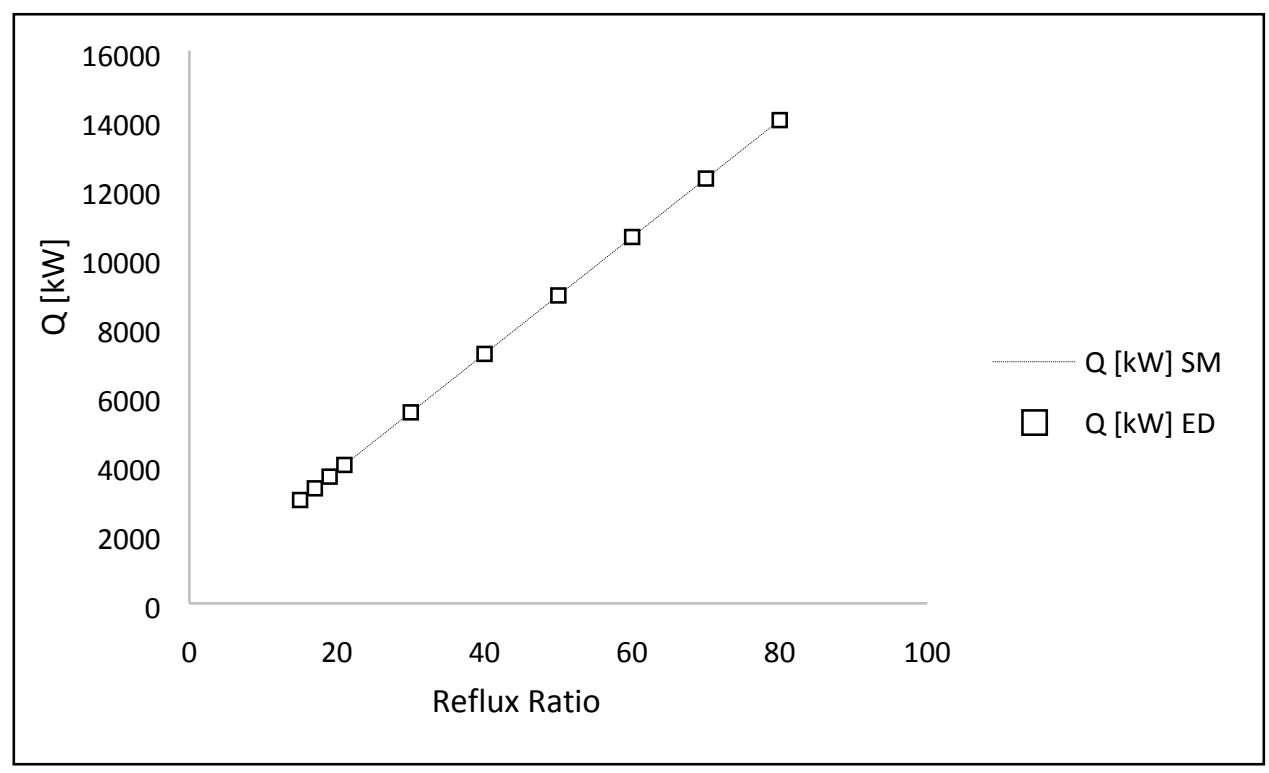

Fig. S4. Reboiler duty of the first column 1 varying the reflux ratio. 


\section{S.M.4 RD technology to produce TEOS}

Figures S5 to S13 (section 2.2.4) shows the molar flow, the condenser duty and reboiler duty by the surrogate model, and the similarities are shown of the values that Aspen Plus ${ }^{\circledR}$ offers, these Figures demonstrates the confiability of the surrogate models obtained in reactive distillation columns for the obtention of TEOS 0.985.0.99.0.995.

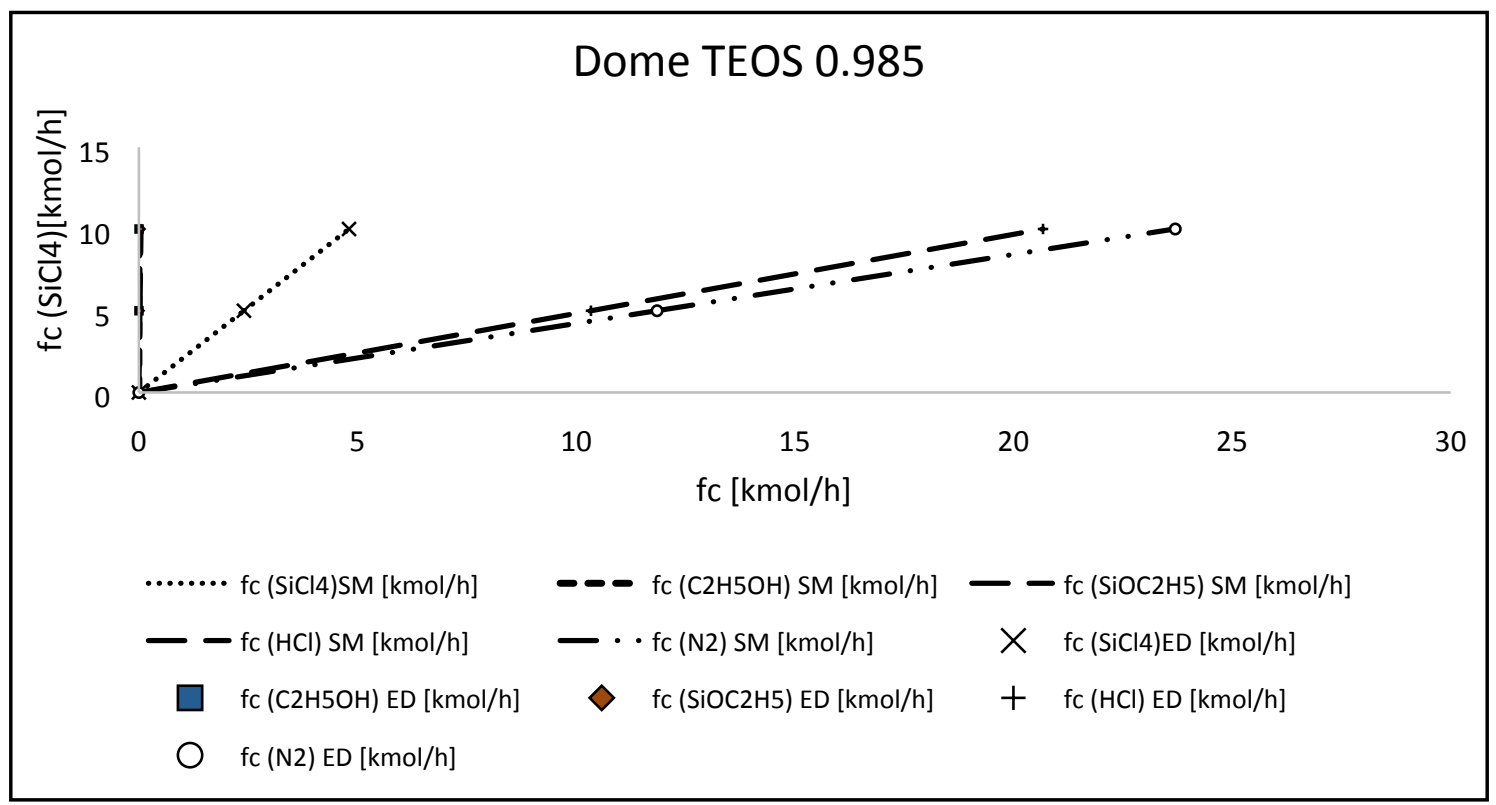

Fig. S5. Molar flow [kmol/h] for each component in the Dome of RDC for TEOS 0.985.

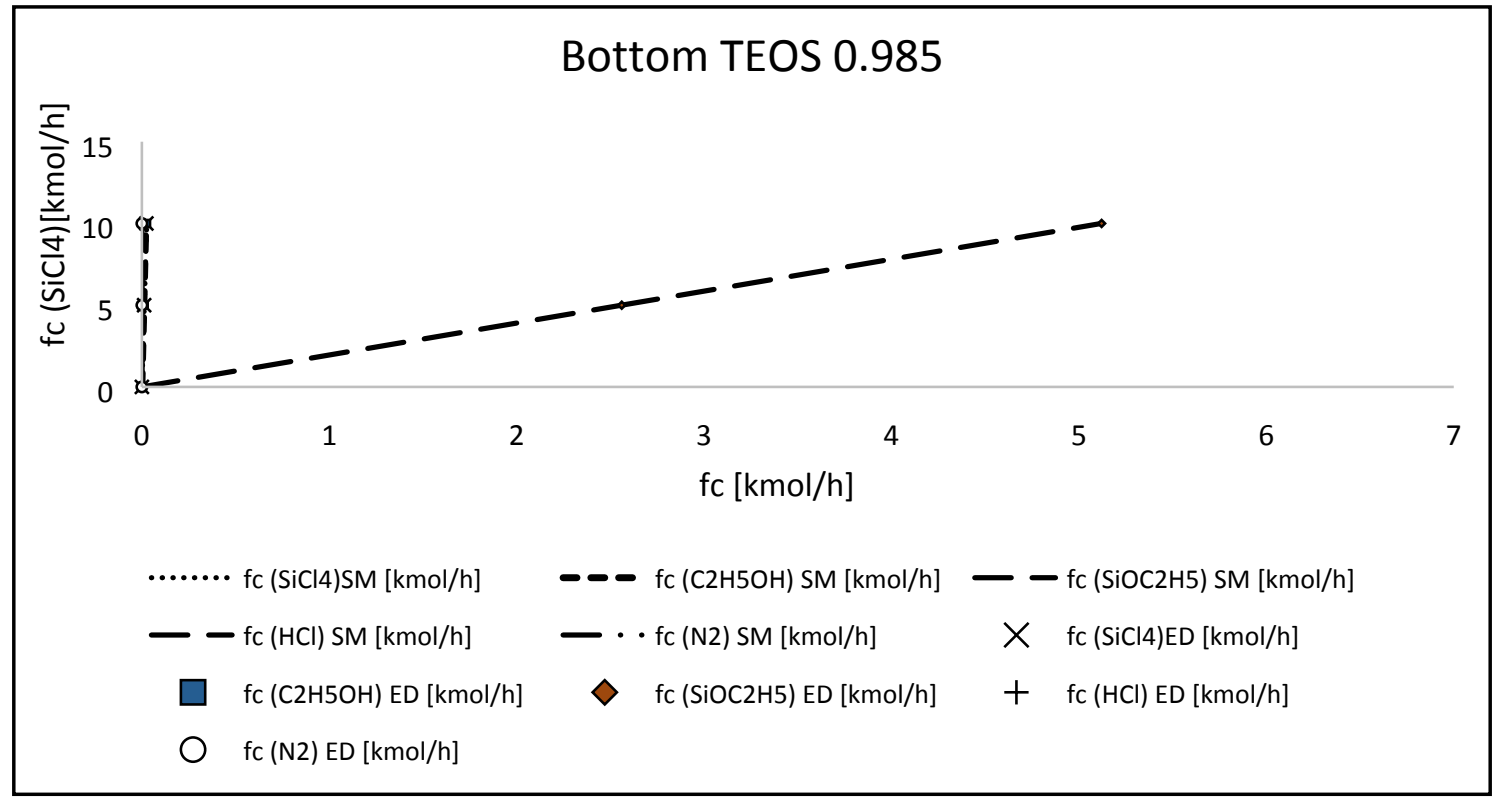

Fig. S6. Molar flow [kmol/h] for each component in the Bottom of RDC for TEOS 0.985. 


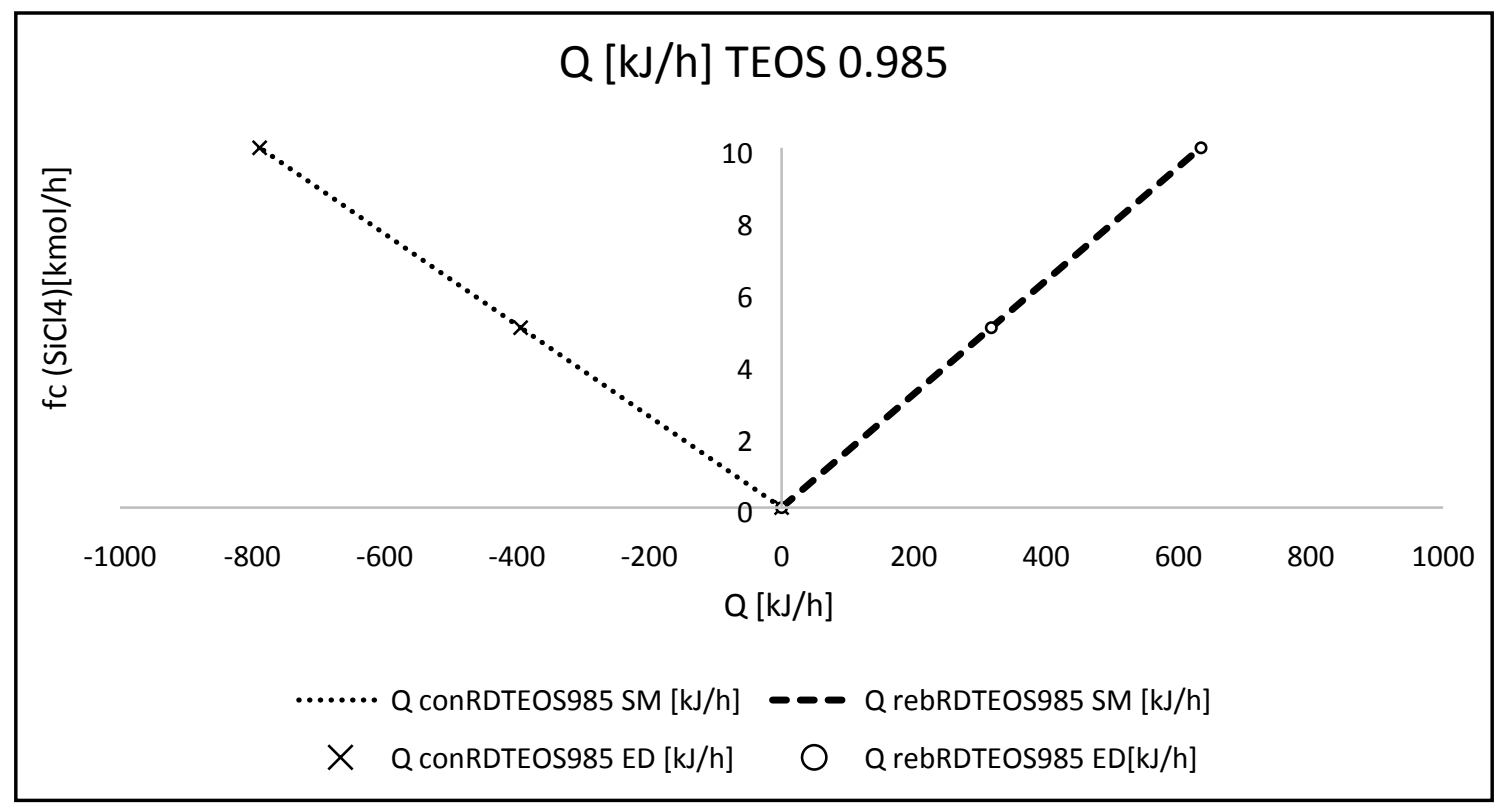

Fig. S7. Energy requirement $[\mathrm{kJ} / \mathrm{h}]$ in the RDC for TEOS 0.985 .

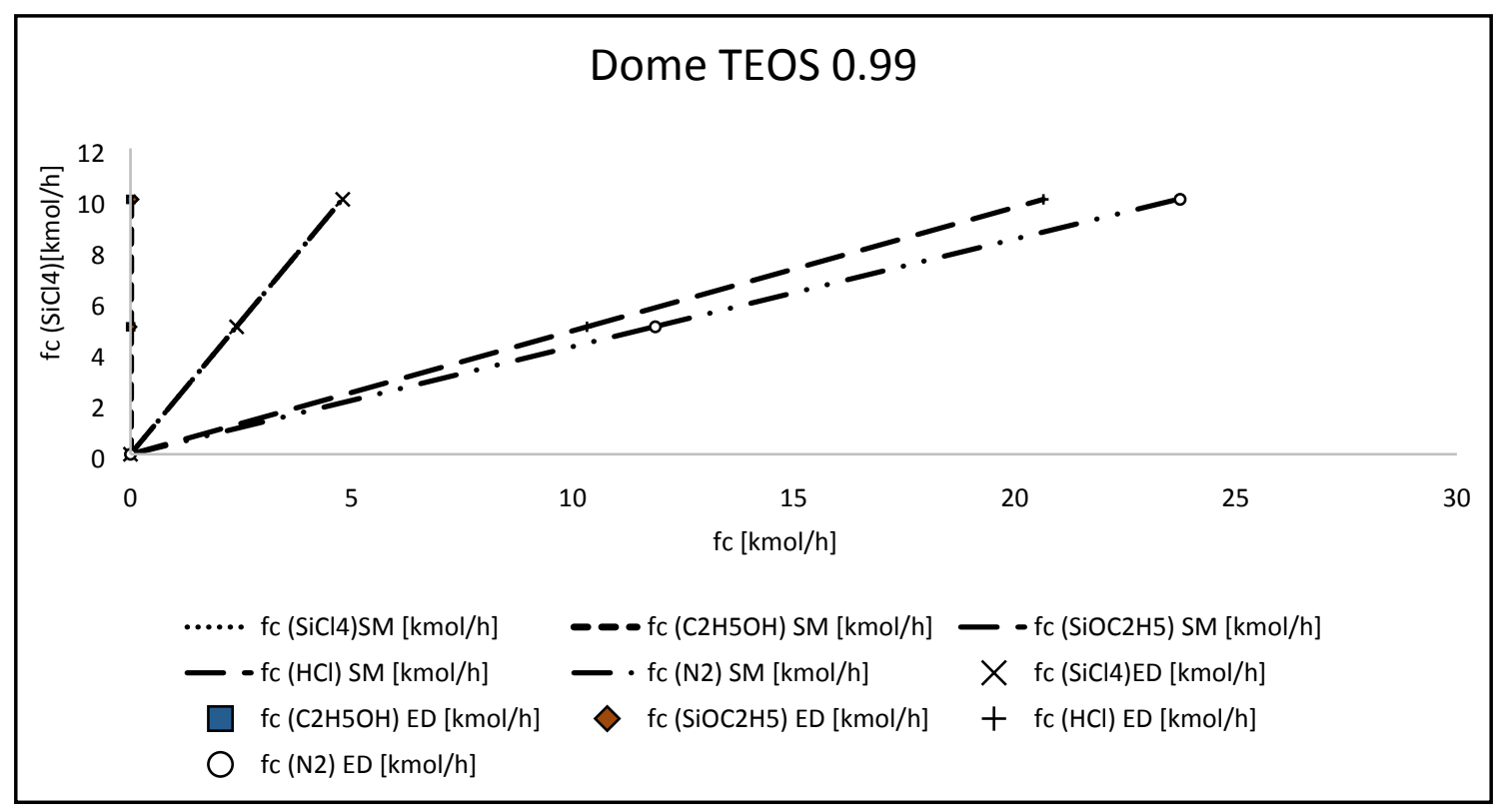

Fig. S8. Molar flow $[\mathrm{kmol} / \mathrm{h}]$ for each component in the Dome of RDC for TEOS 0.99. 


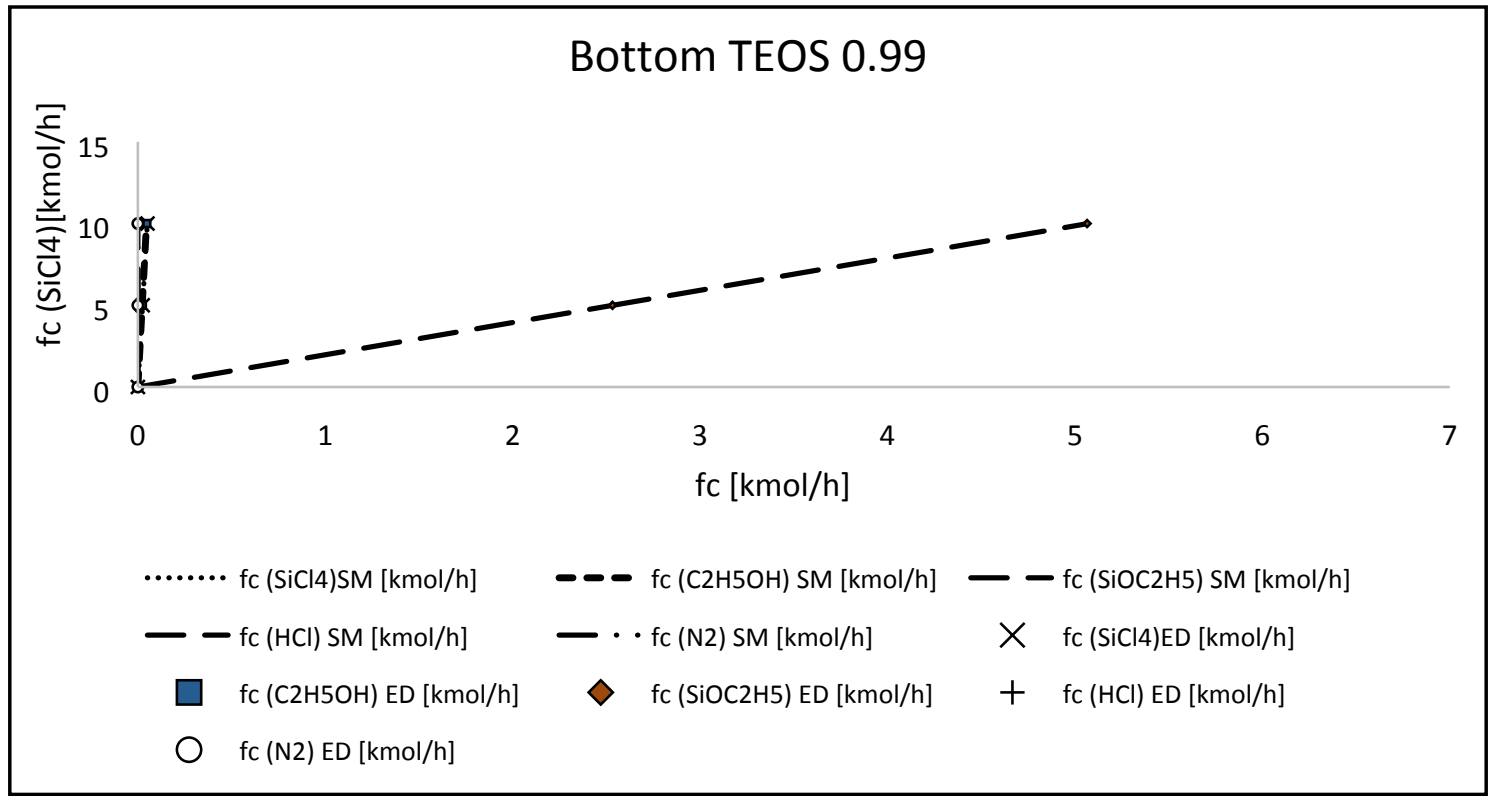

Fig. S9. Molar flow [kmol/h] for each component in the Bottom of RDC for TEOS 0.99.

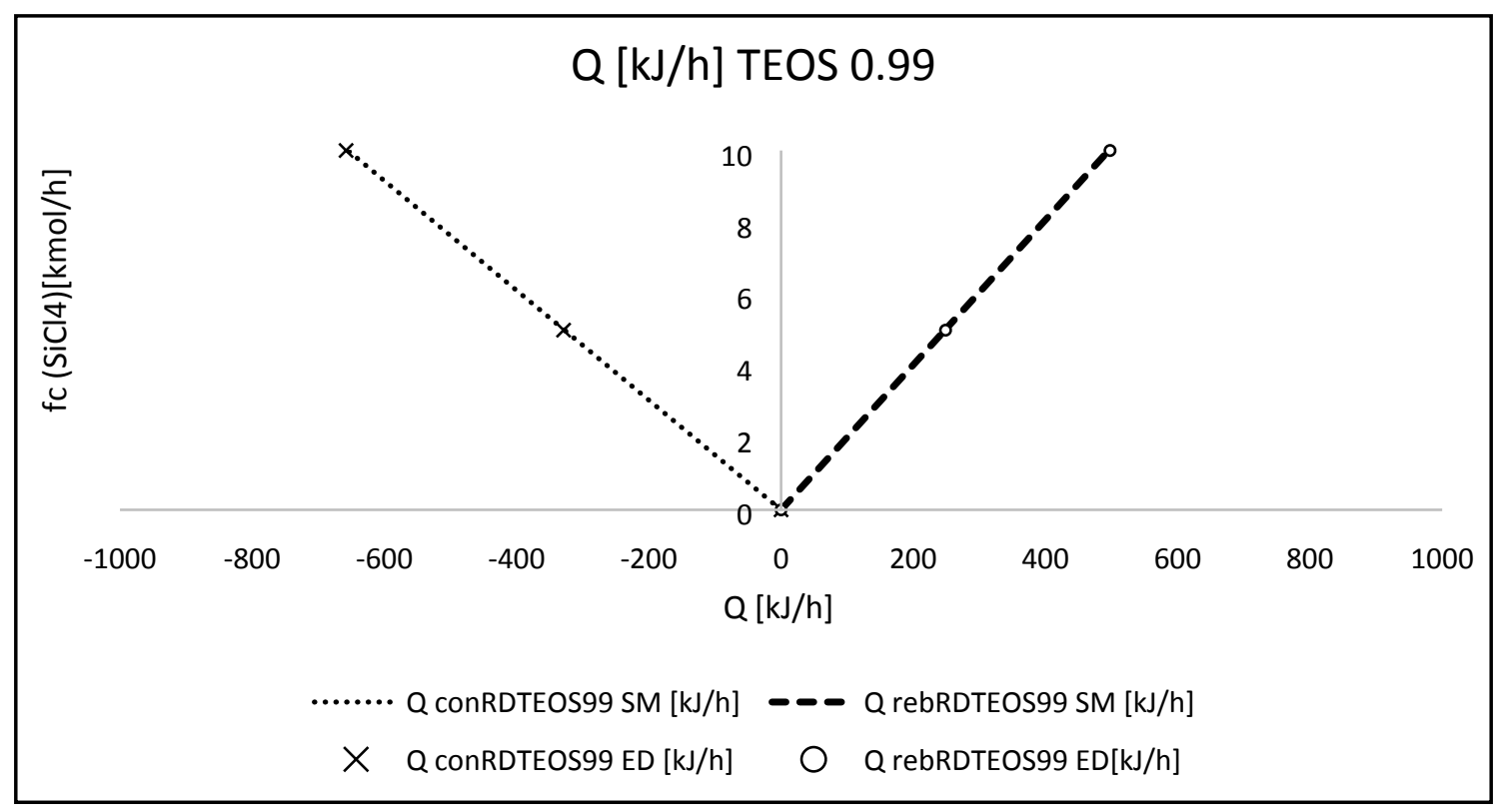

Fig. S10. Energy requirement $[k J / h]$ in the RDC for TEOS 0.99 . 


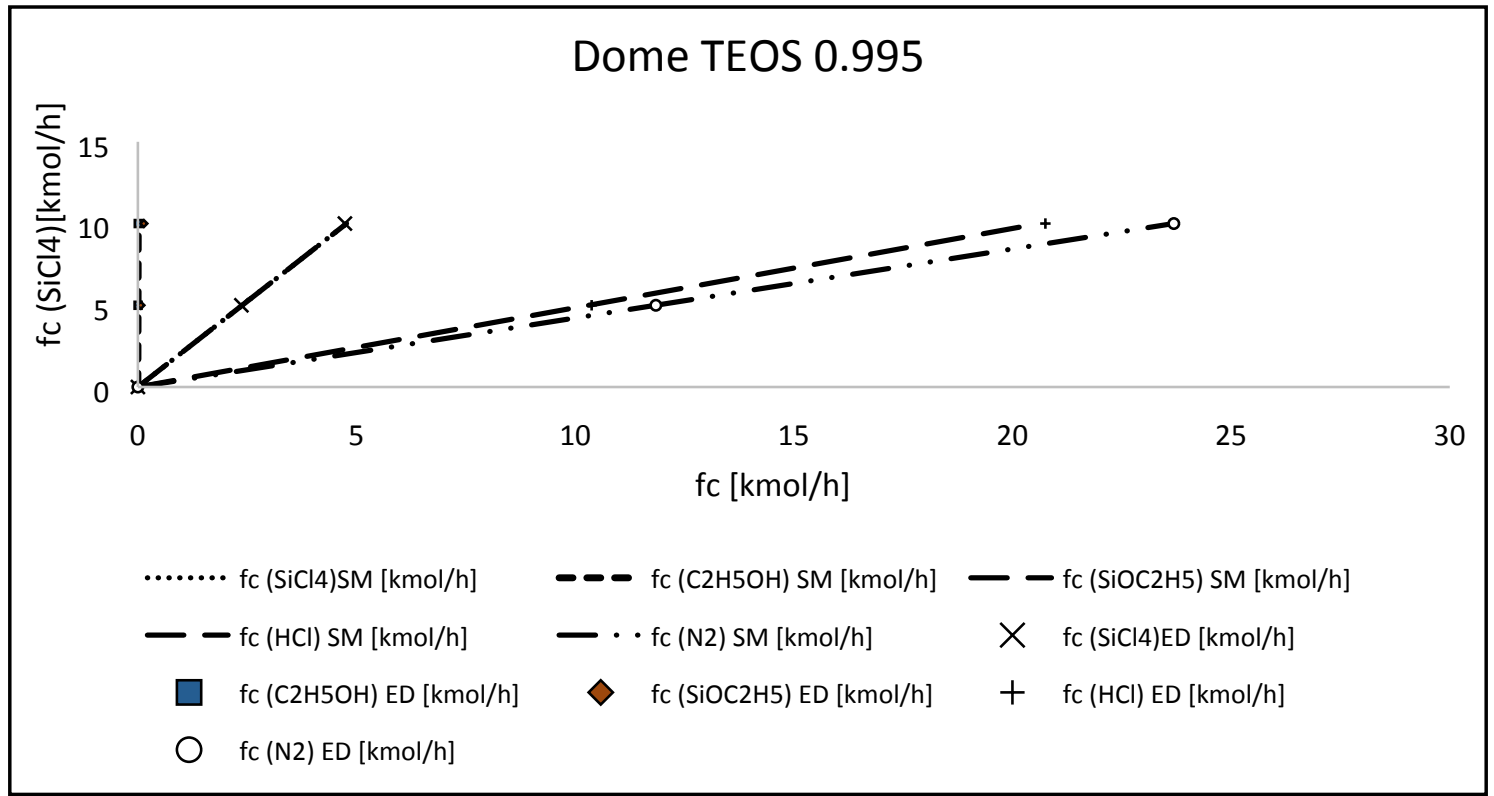

Fig. S11. Molar flow $[\mathrm{kmol} / \mathrm{h}]$ for each component in the Dome of RDC for TEOS 0.995.

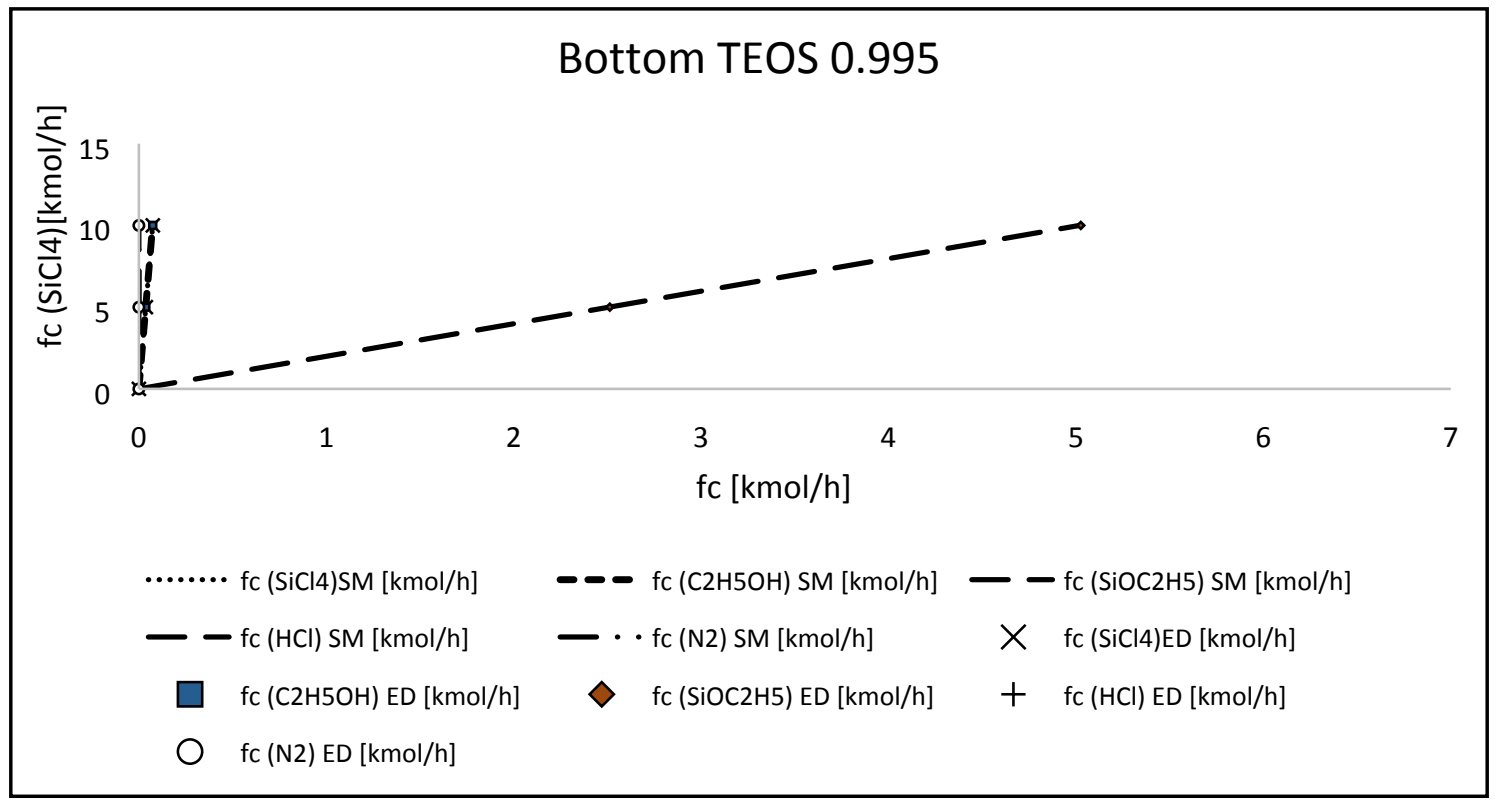

Fig. S12. Molar flow [kmol/h] for each component in the Bottom of RDC for TEOS 0.995. 


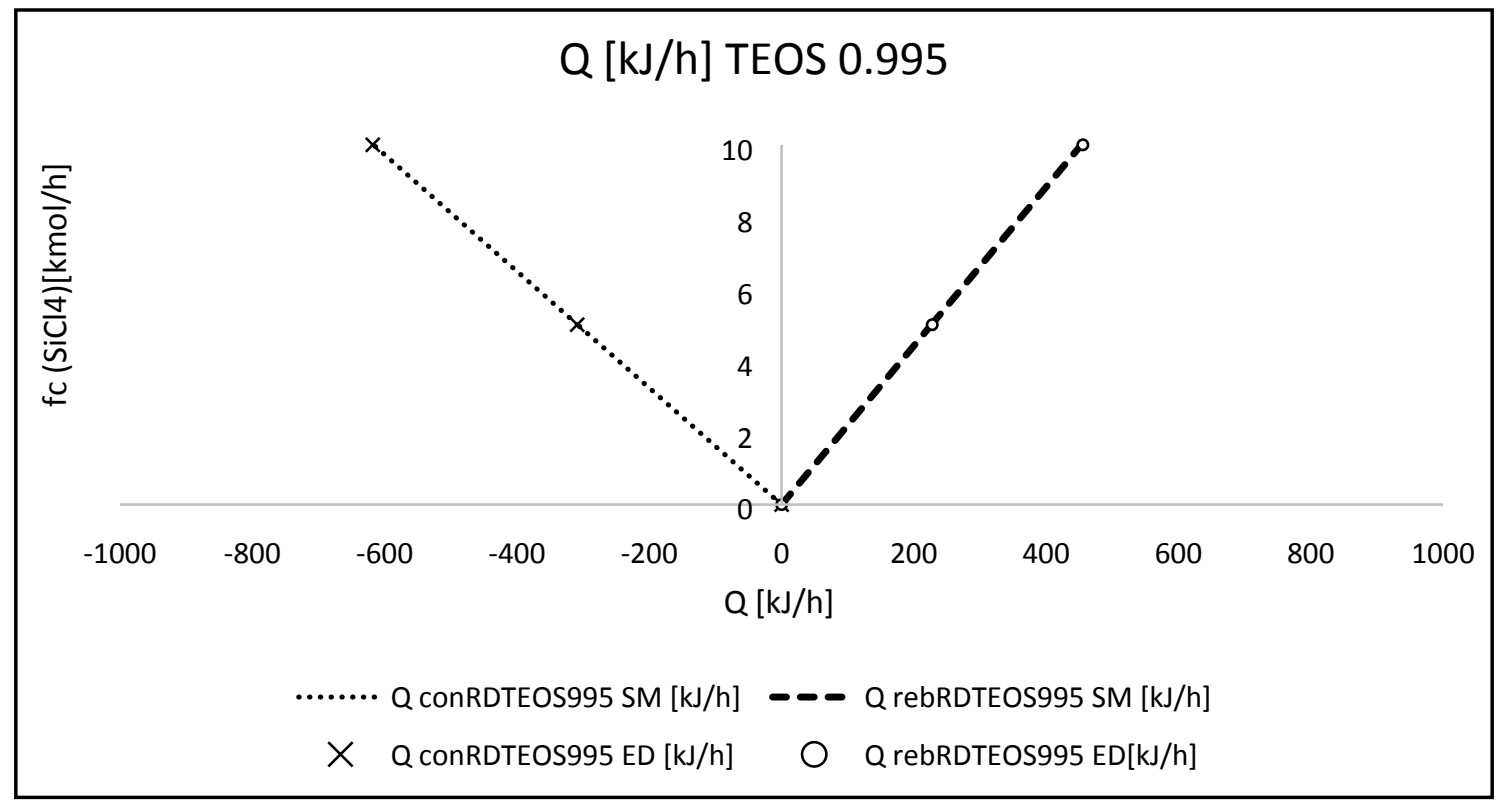

Fig. S13. Energy requirement $[\mathrm{kJ} / \mathrm{h}]$ in the RDC for TEOS 0.995 . 


\section{S.M.5 RD technology to produce silane, monochlorosilane or dichlorosilane}

Figures S14 to S22 displays the molar flow, the condenser duty and reboiler duty by the surrogate model, and the similarities are shown of the values that Aspen Plus $®$ offers, these Figures demonstrates the confiability of the surrogate models obtained in reactive distillation columns for the obtention of $\mathrm{SiH}_{4}, \mathrm{SiH}_{2} \mathrm{Cl}_{2}$ and $\mathrm{SiClH}_{3}$.

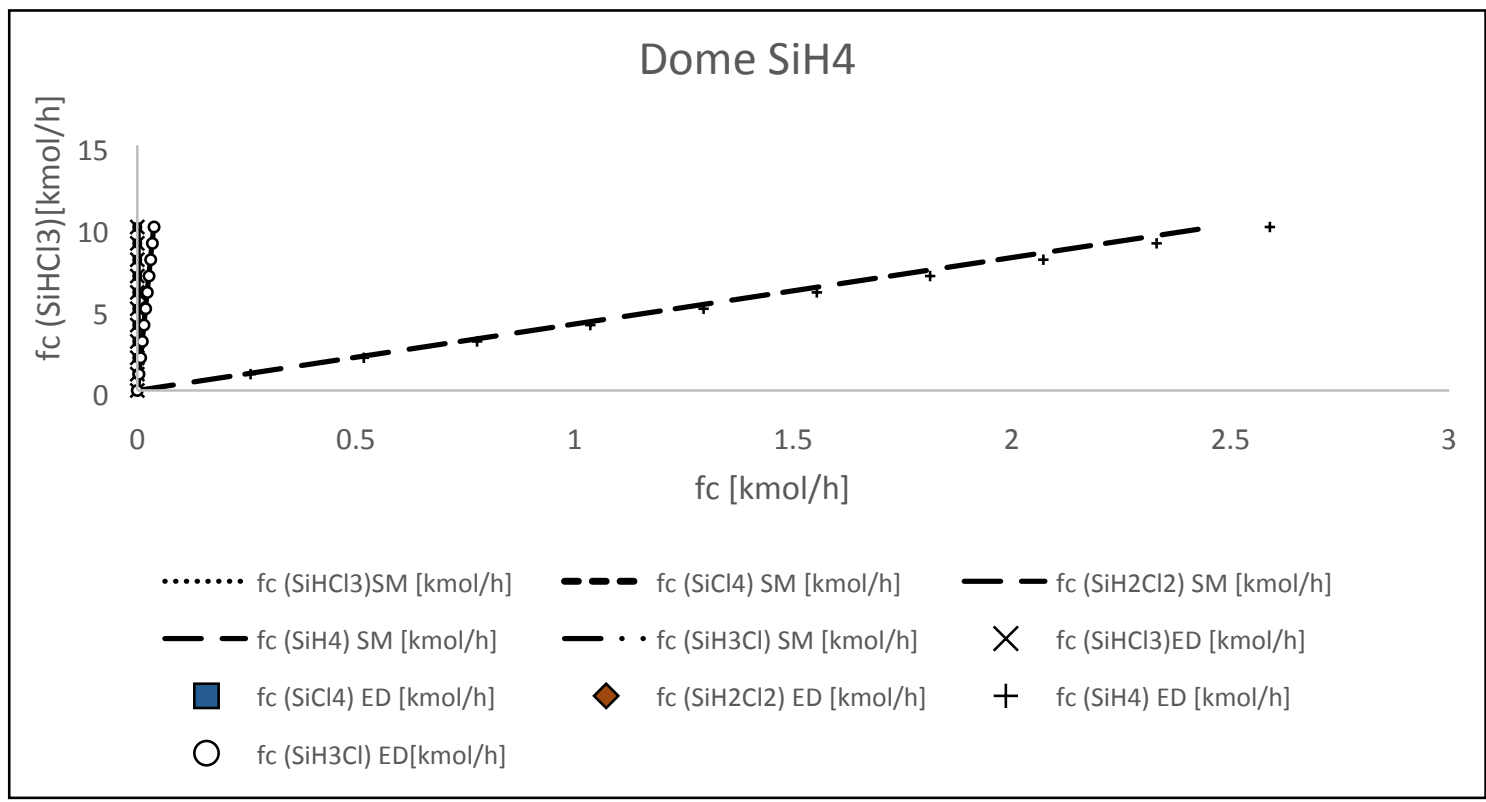

Fig. S14. Molar flow $[\mathrm{kmol} / \mathrm{h}]$ for each component in the Dome of RDC for $\mathrm{SiH}_{4}$.

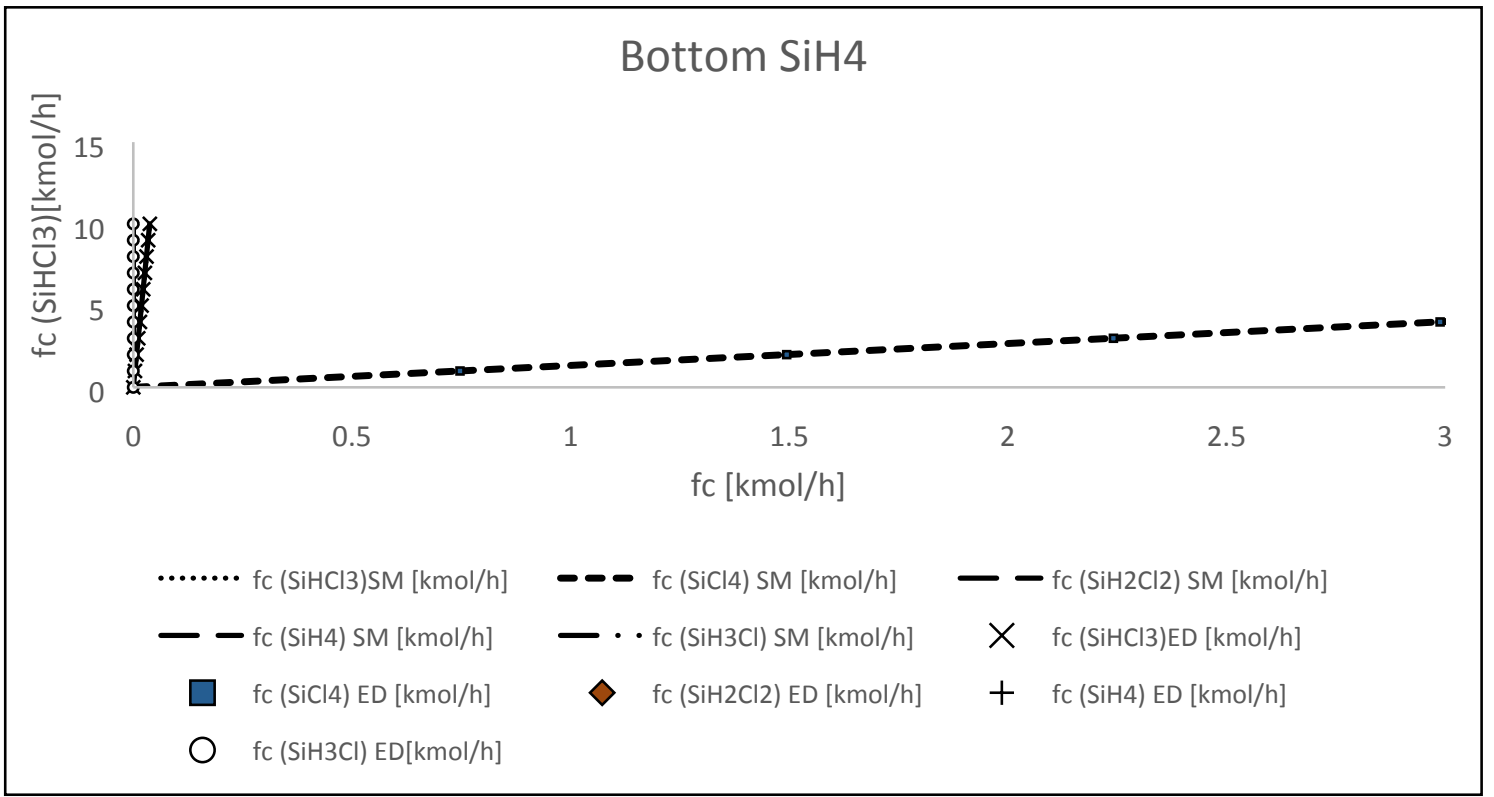

Fig. S15. Molar flow $[\mathrm{kmol} / \mathrm{h}]$ for each component in the Bottom of RDC for $\mathrm{SiH}_{4}$. 


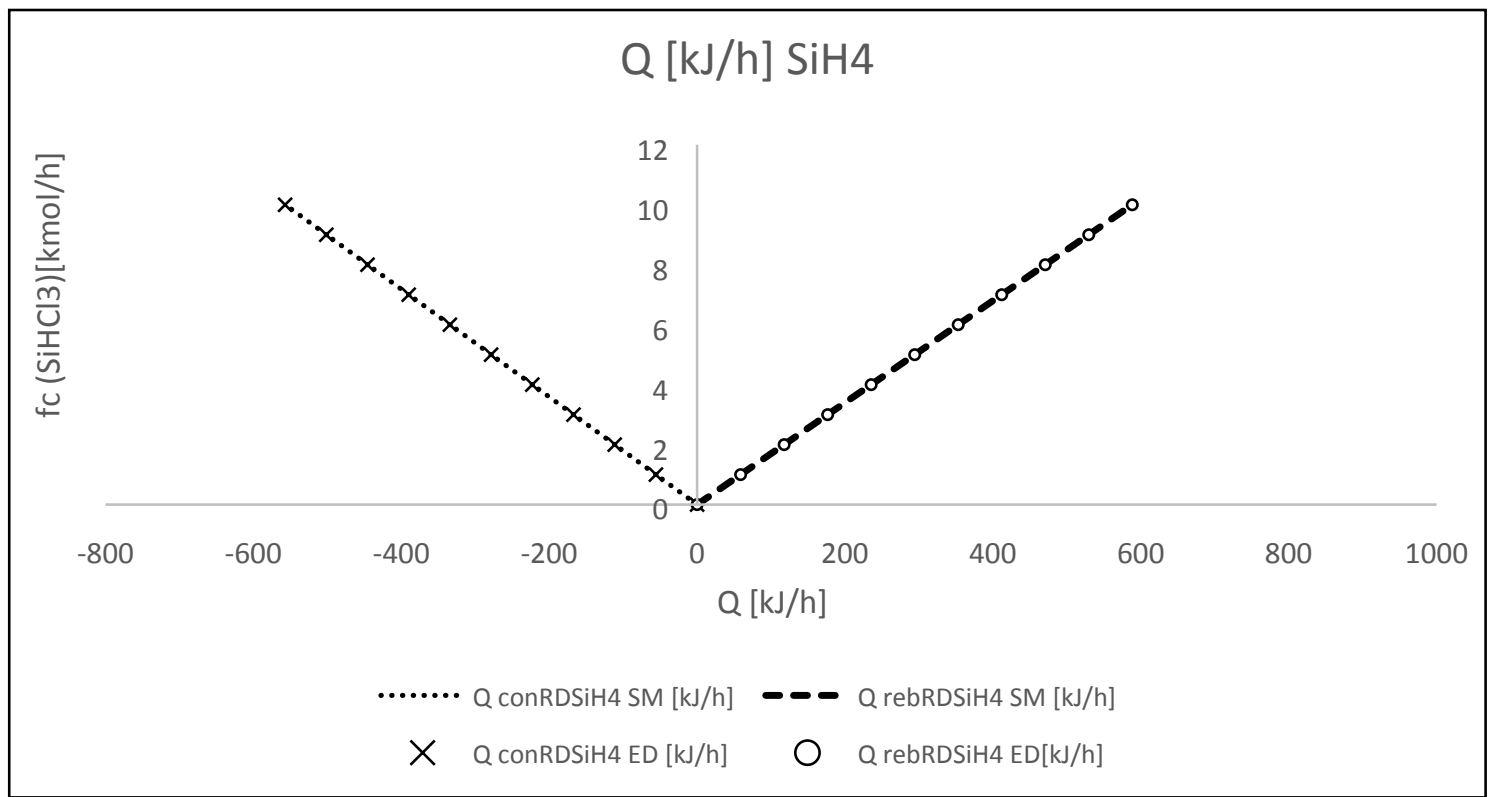

Fig. S16. Energy requirement $[k J / h]$ in the $\mathrm{RDC}$ for $\mathrm{SiH}_{4}$.

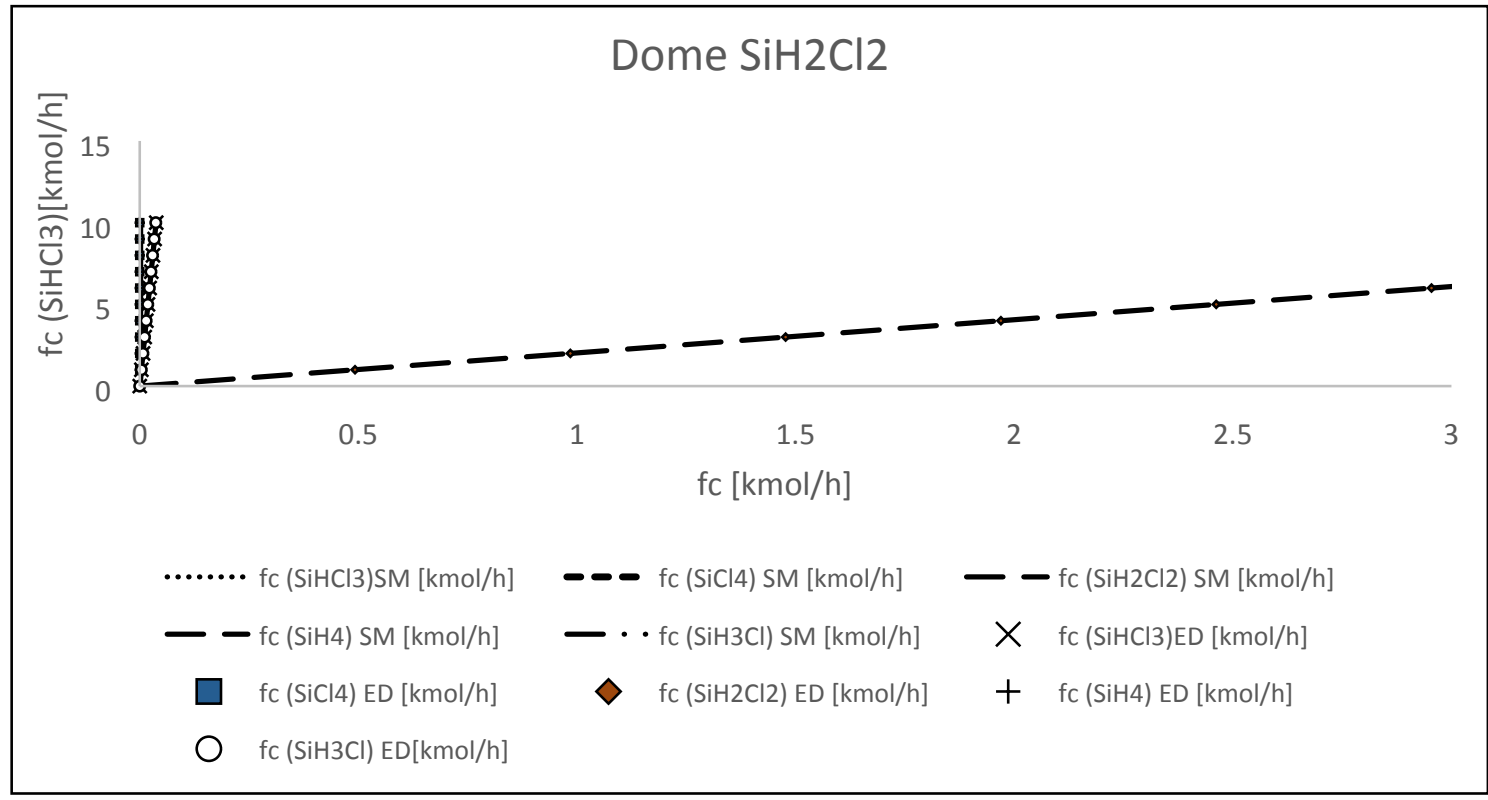

Fig. S17. Molar flow [kmol/h] for each component in the Dome of RDC for $\mathrm{SiH}_{2} \mathrm{Cl}_{2}$. 


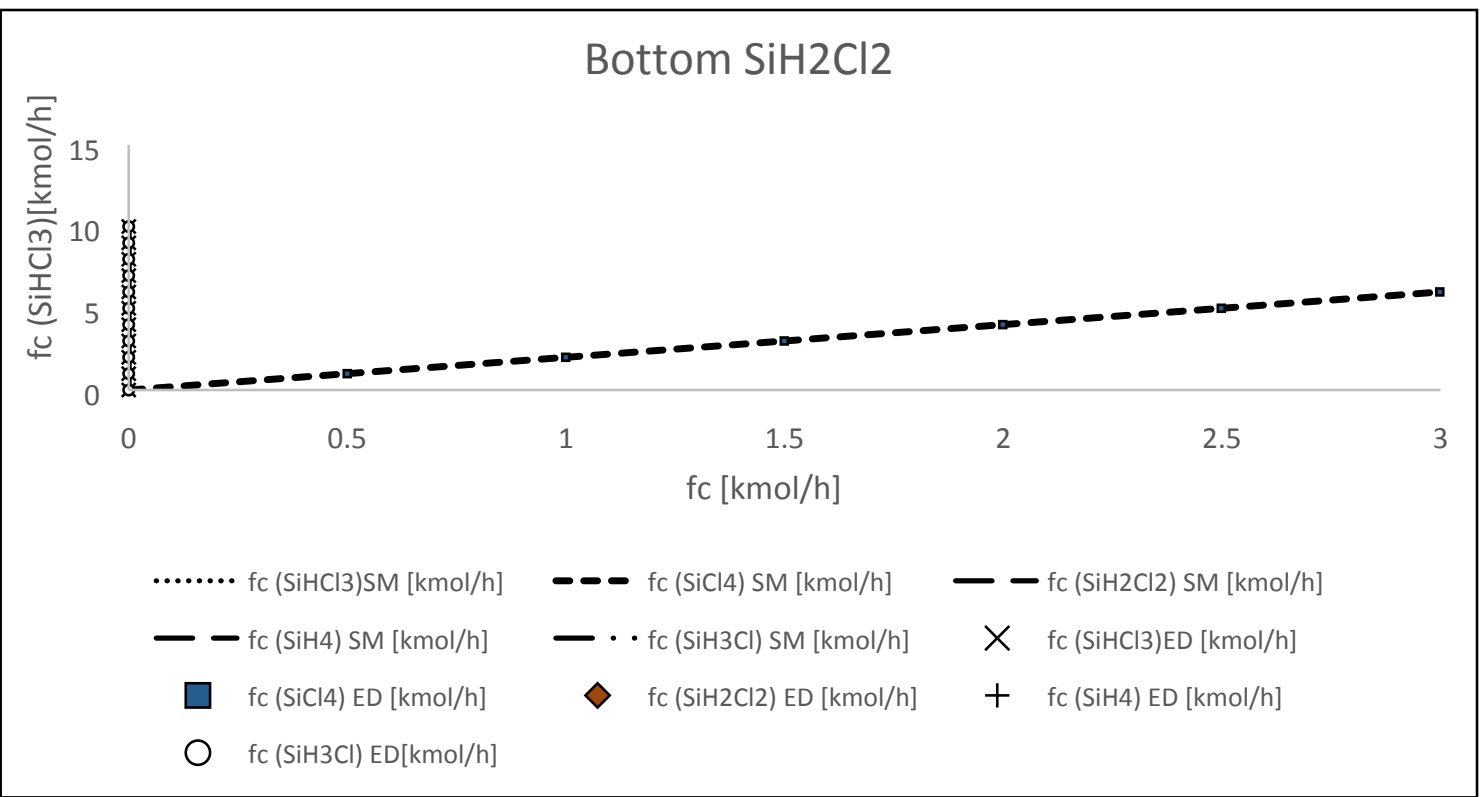

Fig. S18. Molar flow [kmol/h] for each component in the Bottom of RDC for $\mathrm{SiH}_{2} \mathrm{Cl}_{2}$.

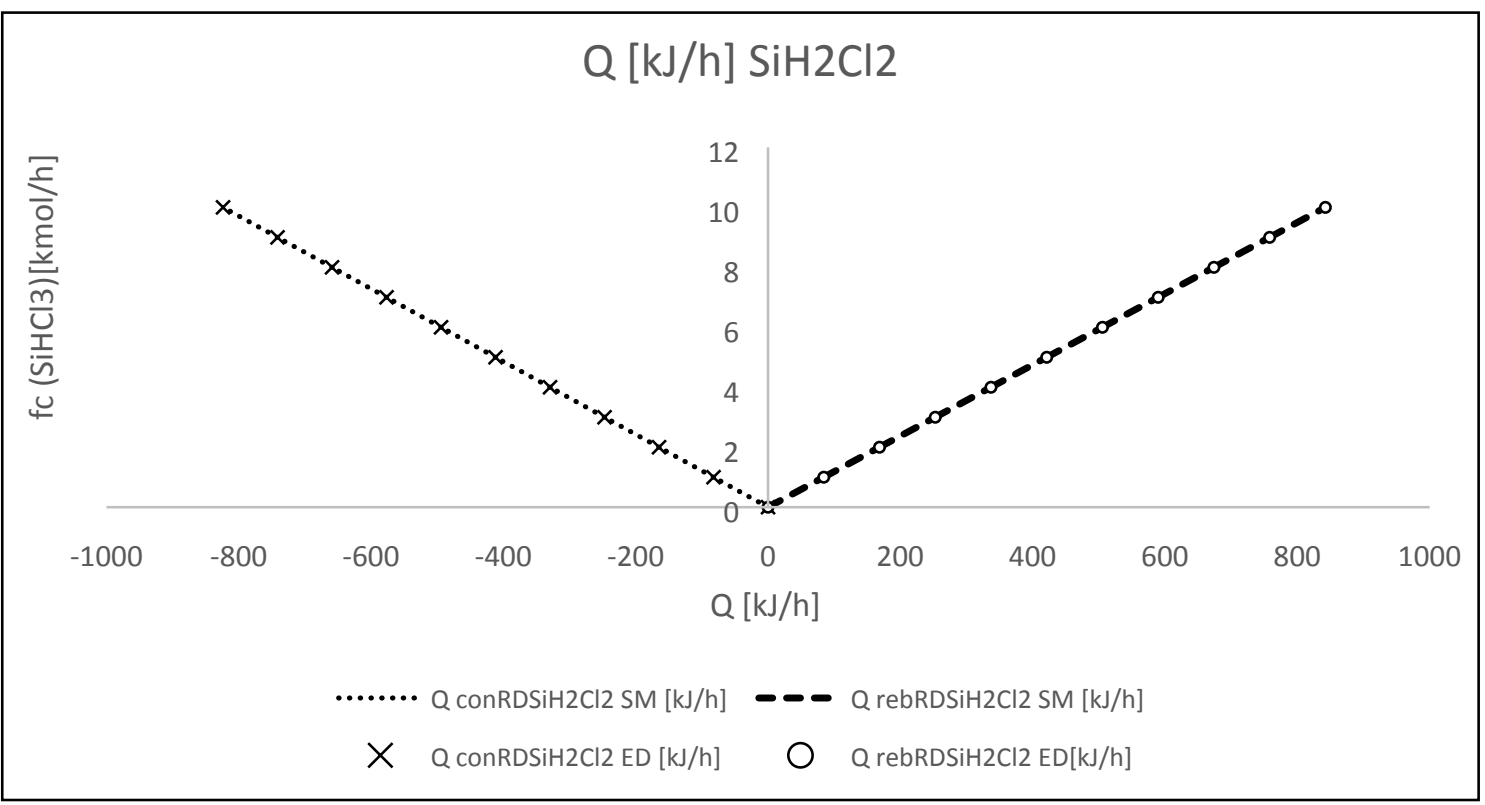

Fig. S19. Energy requirement $[\mathrm{kJ} / \mathrm{h}]$ in the $\mathrm{RDC}$ for $\mathrm{SiH}_{2} \mathrm{Cl}_{2}$. 


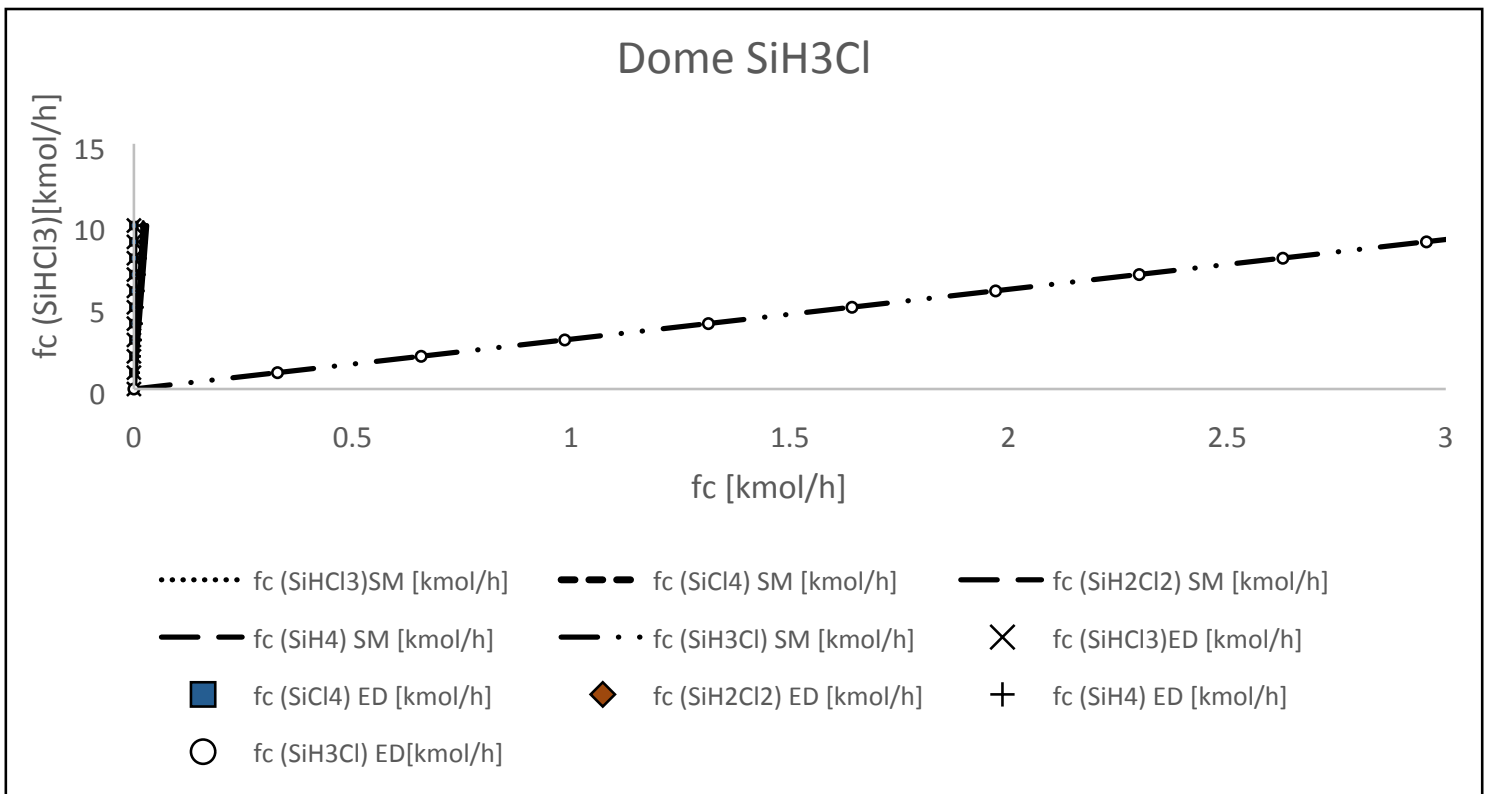

Fig. S20. Molar flow [kmol/h] for each component in the Dome of RDC for $\mathrm{SiH}_{3} \mathrm{Cl}$.

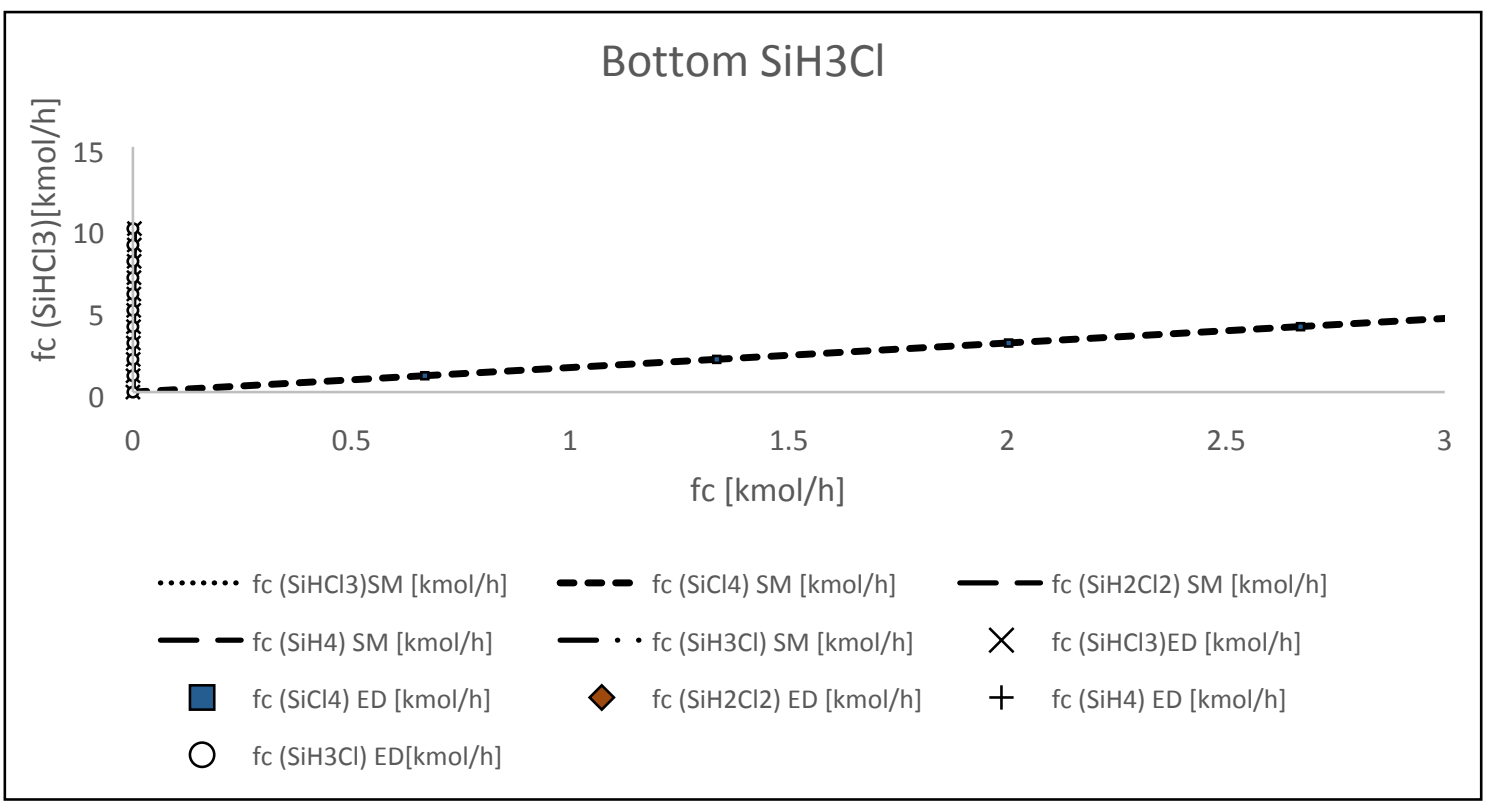

Fig. S21. Molar flow [kmol/h] for each component in the Dome of $\mathrm{RDC}$ for $\mathrm{SiH}_{3} \mathrm{Cl}$. 


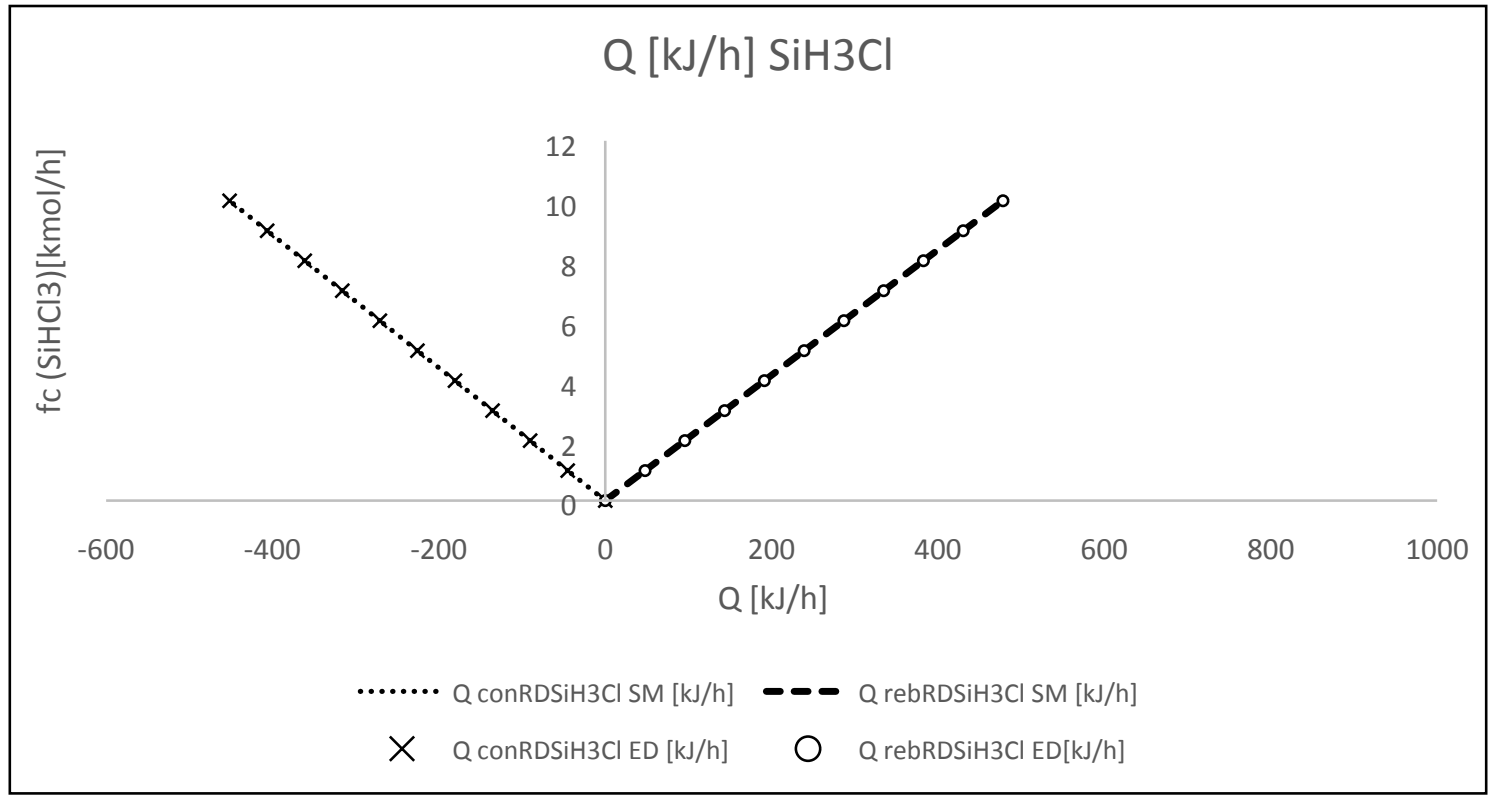

Fig. S22. Energy requirement $[k J / h]$ in the $\mathrm{RDC}$ for $\mathrm{SiH}_{3} \mathrm{Cl}$. 


\section{S.M.6 Siemens Reactor}

Figure S23 offers an overview of the surrogate model (section 2.2.6) obtained with the variables of the temperature and the $\mathrm{H}_{2}$ feed (SM by continuous lines). In Del Coso and Luque's work (2008), the same growth trend of polycrystalline silicon is seen (ED markers), hence the accuracy of the surrogate model is good enough for it used.

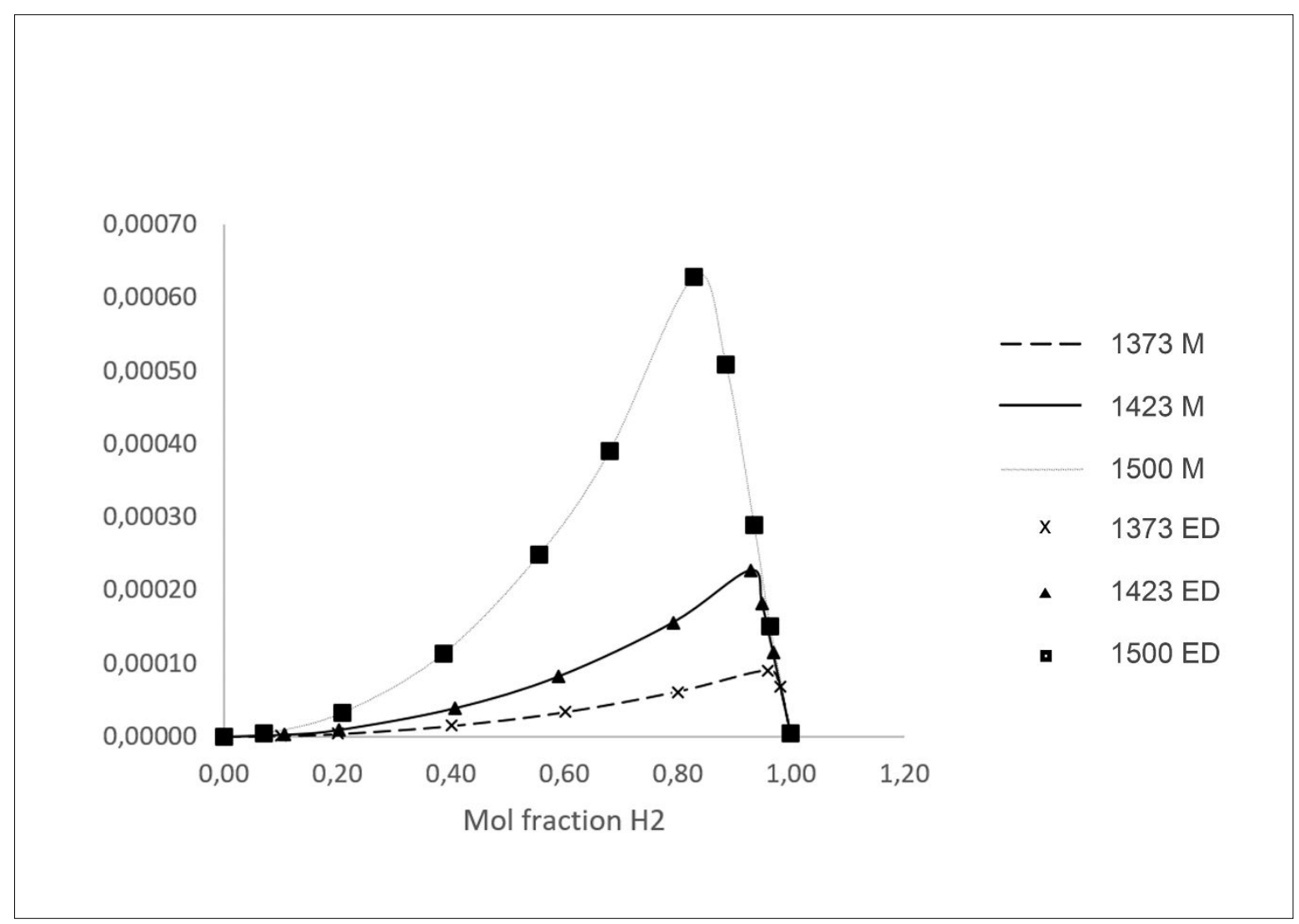

Fig. S23. Kilograms of polycrystalline silicon regarding different road surface temperatures (1373, 1423 , and $1500 \mathrm{~K}$ ) and different mole fraction of $\mathrm{H}_{2}$ (Surrogate Model by continuous lines and experimental data with markers). 